\title{
Will Current Trends in Information Systems Development Lead to More Visible Usage of Socio-technical Approaches?
}

\author{
Steven Alter ${ }^{1}$, Mikko Korpela ${ }^{2}$, Doncho Petkov ${ }^{3}$, and Nancy Russo ${ }^{4}$ \\ ${ }^{1}$ University of San Francisco, U.S.A. \\ alter@usfca.edu \\ ${ }^{2}$ University of Eastern Finland, Finland, and Cape Peninsula University of Technology and \\ Nelson Mandela Metropolitan University, South Africa \\ mikko.kropela@uef.fi \\ ${ }^{3}$ Eastern Connecticut State University, U.S.A. \\ petkovd@easternct.edu \\ ${ }^{4}$ Northern Illinois University, U.S.A. \\ nrusso@niu.edu
}

\section{Background and Goals}

There is broad agreement that socio-technical approaches to systems analysis and design have not been used to their full potential in the information systems field. There are also a number of trends in information systems development (ISD) that might generate opportunities for greater usage of socio-technical approaches.

The panel has several overlapping goals related to current ISD trends and the adoption of socio-technical approaches. The goals include

1. Providing an interesting way of exploring the strengths and limitations of current versions of several socio-technical methods.

2. Identifying ways to extend those methods to make them more useful.

3. Discussing current ISD trends and trying to identify the characteristics and methods from a socio-technical viewpoint that would best support the development environments implied by these trends.

The assumption underlying the entire discussion is that every socio-technical approach has some advantages and some disadvantages, and that much of the value of the panel session is in clarifying those advantages and disadvantages and combining ideas from multiple approaches to come up with a multifaceted method for a particular situation. This discussion can contribute to the evolution of information systems development methods by highlighting the growing importance of sociotechnical approaches in emerging development environments.

\section{Structure and Time Line}

The panel is structured to allow the presenters to explain their initial views, to allow them to interact around practical ISD issues, and to allow the audience to participate 
extensively in the discussion during the last 30 minutes of the panel. The panel will proceed as follows.

Nancy Russo will set the stage by summarizing current ISD trends that might generate greater opportunities for using socio-technical methods in ISD. These trends include more collaboration, along with the breakdown of organizational boundaries to allow greater interaction with external influences; explosive growth in the distributed cocreation of structures and content, often through what are considered Web 2.0 technologies; increased focus on issues of sustainability and social responsibility; and the continuing movement toward a services model of delivery (Bughin et al. 2010).

Mikko Korpela will briefly provide background about activity theory, originally a psychological theory of purposeful human activity mediated by tools and signs, which has been applied widely in educational studies and increasingly in socio-technical design. He will summarize how activity-driven methods for ISD have been used, particularly addressing citizen and community centered service models, codesign, social responsibility, sustainability, and use in Finland, China and Africa (Korpela et al. 2004; Luukkonen et al. 2010). He will also mention some of the limitations of activity theory in relation to possible use in practical ISD situations, especially those in which current ISD trends apply.

Steven Alter will briefly provide background about the work system method, a socio-technical approach that emphasizes evaluation and planning by business professionals who are facing questions about whether a work system operates well enough, and how it can be improved. He will summarize how the work system method has been used in teaching; and its potential value as a tool for business professionals trying to evaluate and analyze IT-reliant systems in organizations (Alter 2010; Truex et al. 2010). He will mention some of its limitations in relation to possible use in practical ISD situations, especially those in which current ISD trends apply.

Don Petkov will explore several issues in using a third socio-technical approach, Checkland's soft systems methodology, in combination with traditional IS development approaches. These include their different epistemological assumptions; the degree of support for stakeholder participation; any potential support for decisions to take a particular action; difficulties in transitioning from SSM analysis to traditional IS development models; degree of support for analyzing of both the technical and social aspects of a work system; and availability of means to promote learning (Petkov et al. 2008; Petkov et al. 2007). Then he will explore whether similar conclusions may apply to Alter's work system method or the activity driven methods for IS development by Korpela and his group.

An interactive discussion by the panel members will focus on the question giving title to the panel: Will current trends in information system development lead to more visible usage of socio-technical approaches? After the panel members have provided their comments, audience members will be welcomed to join the discussion with their own observations and suggestions.

\section{Panelists}

Steven Alter is a Professor of Information Systems at the University of San Francisco, San Francisco, California. His research for over a decade has concerned developing systems analysis concepts and methods that can be used by typical 
business professsionals and can support communication with IT professionals. His publications include a 2006 book, The Work System Method: Connecting People, Processes, and IT for Business Results, and many related articles in journals and conference proceedings.

Mikko Korpela is a Research Director in Health Information Systems Research and Development, School of Computing, at the University of Eastern Finland, in Kuopio, Finland, as well as an Adjunct Professor at Cape Peninsula University of Technology, Cape Town, and an Honorary Professor at Nelson Mandela Metropolitan University in Port Elizabeth, South Africa. He has studied ISD with an activitytheoretical approach since the late 1980s, collaborating with several African universities. He has published in IFIP WG 8.2 and WG 9.4 conferences and elsewhere.

Don Petkov is a Professor of Information Systems at Eastern Connecticut State University, Willimantic, Connecticut. His research explores the application of SSM and other systems approaches in software engineering, telecommunications planning, and environmental management. His papers have appeared in The Journal of Systems and Software, Decision Support Systems, Information Resources Management Journal, Telecommunications Policy, and elsewhere.

Nancy L. Russo is a Professor of Information Systems in the Operations Management and Information Systems Department at Northern Illinois University, DeKalb, Illinois. She studies information systems development and implementation, and is the co-author of Information Systems Development: Methods-in-Action. Her work has appeared in Information Systems Journal, Communications of the ACM, European Journal of Information Systems, and Information Technology \& People

\section{References}

Alter, S.: Bridging the Chasm Between Sociotechnical and Technical Views of Systems in Organizations. In: 31st International Conference on Information Systems (2010)

Bughin, J., Chui, M., Manyika, J.: Clouds, Big Data, and Smart Assets: Ten Tech-Enabled Business Trends to Watch. McKinsey Quarterly, August 1-14 (2010)

Korpela, M., Mursu, A., Soriyan, A., Eerola, A., Häkkinen, H., Toivanen, M.: Information Systems Research and Development by Activity Analysis and Development: Dead Horse or the Next Wave? In: Kaplan, B., Truex III, D.P., Wastell, D., Wood-Harper, A.T., De Gross, J.I. (eds.) Information Systems Research: Relevant Theory and Informed Practice. IFIP TC8/WG 8.2 20th Year Retrospective, pp. 453-471. Kluwer Academic, Boston (2004)

Luukkonen, I., Korpela, M., Mykkänen, J.: Modelling Approaches in the Early Phases of Information Systems Development. In: IT to Empower - 18th European Conference on Information Systems (2010)

Petkov, D., Edgar-Nevill, D., Madachy, R., O’Connor, R.: Information Systems, Software Engineering and Systems Thinking? Challenges and Opportunities. International Journal on Information Technologies and the Systems Approach 1, 62-78 (2008)

Petkov, D., Petkova, O., Andrew, T., Nepal, T.: Mixing Multiple Criteria Decision Making with Soft Systems Thinking Techniques for Decision Support in Complex Situations. Decision Support Systems 43, 1615-1629 (2007)

Truex, D., Alter, S., Long, C.: Systems Analysis for Everyone Else: Empowering Business Professionals Through a Systems Analysis Method that Fits Their Needs. In: IT to Empower - 18th European Conference on Information Systems (2010) 